*Elspeth Guthrie, Senior Lecturer in Psychiatry, University of Manchester, Rawnsley Building. CMHT, Manchester M13 9BX; Teresa Tattan, Research Fellow, University of Manchester, Edwina Williams, Specialist Registrar, Westminster and Chelsea Hospitals, London;
Dawn Black, Consultant Psychiatrist, Hope Hospital, Salford; and Himant Bacliocotti, Specialist Registrar, Nottingham

*Correspondence

\title{
First psychosis liaison unit family education programme
}

\author{
Eric Morris, Catie Harris and Lynley Nolan
}

\begin{abstract}
Aims and methods This study presents an evaluation of an education programme for families whose relative has experienced a first episode of psychosis. Participants attended a five-week programme and were asked to rate their level of knowledge and confidence in managing the illness before and after the education sessions.

Results Two consecutive groups of relatives $(n=9$ : $n=11$ ) attended the programme. Comparison of knowledge and confidence ratings before and after the education sessions demonstrated significant levels of change at the final session for both groups.

Clinical implications Education for relatives of people experiencing psychosis for the first time is an important component in community management. Such education improves the knowledge and confidence of relatives in coping with the illness, possibly leading to a more accepting and less stressful family environment, reducing the risk of relapse and promoting the psychological health of the patient.
\end{abstract}

Assistance in the family management of psychosis can produce significant reductions in relapse rate and produce benefits for the general psychological well-being of the individual with a psychotic illness (Falloon et al, 1982). A reduction in subsequent relapses after a first episode of illness may help prevent chronicity and associated disability (Jackson \& Birchwood, 1996).

An important component of the family management process is education of the family regarding the illness, the role of various treatment providers, problem-solving and managing crises, and the variety of services available to the family and the individual (Tarrier \& Barrowclough et al, 1987).
We describe a family education programme which is part of the first psychosis service (First Psychosis Liaison Unit; FPLU) based at the Mills Street Centre, Perth. Western Australia. The Mills Street Centre services a socio-economically diverse catchment area of around 120000 adults. The FPLU, a community-based initiative, became operational in late August 1995 and aims to facilitate the provision of personalised comprehensive care for young people (aged 16 to 35 years) experiencing a first episode of psychosis. This is achieved by fostering effective links between relevant health, welfare, employment and education-related agencies. FPLU provides case management for individuals in the first episode of a psychotic illness and operates as an adjunct to the existing multi-disciplinary mental health service. Case management is conducted by clinical liaison officers, who are trained mental health professionals from either social work, community mental health nursing or occupational therapy backgrounds working in generic positions. Other components of the FPLU service include individual and family support, community education, promotion of early identification of psychosis and clinical research.

The FPLU Family Education Programme aims to provide family members with accurate information and to encourage the use of this information to enhance familial adjustment to having a member with a psychotic illness. It is expected that this will enable more appropriate use of services, better communication between family members and treatment providers, and improve the coping skills of the family. In addition the programme allows the participants to meet other families who are facing the same 
difficulties. It reinforces to participants that they are not alone in coping with these difficulties, there are services available for them, and that they can have an important role in the management of the illness.

\section{Format of the programme}

The programme is available to family members and friends of people who have recently experienced their first episode of psychosis. It is run by two clinical liaison officers and a clinical psychologist with guest speakers from the multidisciplinary team and support agencies. Sessions of two hours each are conducted over a five-week period, covering the following: Session 1, introduction of First Psychosis Liaison Unit, about psychosis; Session 2, the Mental Health Act, medication, the role of the psychiatrist; Session 3, roles of the multi-disciplinary team, psychosocial treatment; Session 4, living with a person with psychosis, crisis management, early warning signs; Session 5, accessing help, support groups.

\section{Evaluation of the programme}

Evaluation of the programme is by a questionnaire designed to assess self-reported levels of knowledge about psychosis; services available to individuals and families; and level of confidence in managing the illness and dealing with crises. Ratings are on a five-point scale $(1=$ not confident, 3=somewhat confident, 5=very confident). Assessments are performed prior to the first session and after the final session. A consumer satisfaction measure is also administered in the final session.

We report here on the first two family education groups. The first group (Group 1) consisted of nine relatives (seven mothers, two fathers). The second group (Group 2) consisted of 11 relatives (six mothers, four fathers and one sister). These two groups of family members differed in terms of length of time in contact with psychiatric services, with the Group 1 having longer contact from index admission (34 weeks on average) compared with the second group. Many of the members of Group 1 had previously accessed support and education from other local support agencies. Group 2 consisted of family members whose relative had been recently admitted to psychiatric care (within 12 weeks of index admission), families having minimal access to education.

\section{Knowledge and confidence}

Comparison of Group 1 and 2 on baseline levels of self-rated knowledge and confidence showed significant differences (all at $P<0.01$ ) between the groups on all ratings, with the more experienced Group 1 having higher scores on all measures.

Baseline and post-education scores were compared for both groups showing significant gains made at the end of the education sessions (see Table 1). For each group there was a significant difference from baseline to post-education in knowledge about psychosis, knowledge about services, confidence about management of the illness and confidence in dealing with a crisis.

Comparison of the two groups post-education scores showed no significant differences in level of knowledge and confidence. This suggests that despite Group 2's minimal exposure to education the programme was able to produce changes up to the level of the more experienced Group 1.

Table 1. Pre- and post-education scores for two family groups

\begin{tabular}{|c|c|c|c|}
\hline & $\begin{array}{l}\text { Pre-education } \\
\text { mean (s.d.) }\end{array}$ & $\begin{array}{l}\text { Post-education } \\
\text { Mean (s.d.) }\end{array}$ & $\boldsymbol{P}$ \\
\hline \multicolumn{4}{|l|}{ Group I $(n=9)$} \\
\hline \multicolumn{4}{|l|}{ Knowledge } \\
\hline Psychosis & $2.70(1.06)$ & $3.89(0.92)$ & $P<0.05$ \\
\hline Services & $2.70(0.95)$ & $4.11(0.78)$ & $P<0.01$ \\
\hline \multicolumn{4}{|l|}{ Confidence } \\
\hline Managing illness & $2.75(0.63)$ & $3.56(0.73)$ & $P<0.05$ \\
\hline Managing crises & $2.65(0.67)$ & $3.33(0.50)$ & $P<0.05$ \\
\hline \multicolumn{4}{|l|}{ Group $2(n=11)$} \\
\hline \multicolumn{4}{|l|}{ Knowledge } \\
\hline Psychosis & $1.80(0.78)$ & $3.78(0.83)$ & $P<0.0001$ \\
\hline Services & $2.20(1.03)$ & $4.00(0.71)$ & $P<0.001$ \\
\hline \multicolumn{4}{|l|}{ Confidence } \\
\hline Managing illness & $2.30(1.16)$ & $3.78(0.67)$ & $P<0.01$ \\
\hline Managing crises & $2.30(0.95)$ & $3.56(0.73)$ & $P<0.01$ \\
\hline
\end{tabular}




\section{Consumer satisfaction}

Consumer satisfaction ratings were strongly supportive of the programme and participants indicated that the sessions fulfilled their needs in terms of education about the various aspects of first-episode psychosis and treatment. Comments made by a number of the participants stated that they wished that this service, and greater support, was available earlier in the admission of their relative (especially those in Group 1) and that there was wider community education about psychosis. A number of participants indicated that if there had been wider community knowledge about psychosis their relative would have been referred to psychiatric services earlier in the course of illness.

\section{Comment}

This programme appears to have value in educating family members about psychosis. Follow-up assessment after a three-month interval will ascertain whether there is a maintenance of gains made from the sessions. It is hoped that future groups will consist of family members earlier in the course of their relative's illness. Future evaluation is aiming to ascertain whether there is reduced family burden as a result of these sessions, in addition to reduced levels of stress in family members.

It must be stressed that this programme is one component of a general treatment strategy to engage families in the management of psychotic illness. Thus, families may require more intensive input in improving skills such as communication, problem-solving, relapse prevention and crisis management.

\section{References}

BarrowClough, C. TARRIER, N.. WATTS, S., et al (1987) Assessing the functional value of relative's knowledge about schizophrenia: a preliminary report. British Journal of Psychiatry. 151, 1-8.

FALLOON, I. R. H., BOYD, J. L., MCGiLl. C. W., et al (1982) Family management in the prevention of exacerbations of schizophrenia. New England Joumal of Medicine. 306, 1437-1440.

JACKSON, C. \& BIRCHWOOD, M. J. (1996) Early intervention in psychosis: opportunities for secondary prevention. British Journal of Clinical Psychology, 35, 487-502.

TARRIER, N. \& BARROWCLOUGH. C. (1986) Providing information to relatives about schizophrenia: some comments. British Journal of Psychiatry. 149, 458-463.

Eric Morris, Clinical Psychologist, Catie Harris, Clinical Liaison Officer; and Lynley Nolan, Clinical Liaison Officer, First Psychosis Liaison Unit, Bentley Health Service, Western Australia

\title{
Children's needs when their mothers are admitted to psychiatric units
}

\author{
Leonor Montoliu Tamarit and A. Yin-Har Lau
}

\begin{abstract}
Aims and methods Due to a concern over the low level of referrals of children to the child and adolescent psychiatry team, an audit was designed to investigate the possible causes. An audit was undertaken in which the case notes of 100 consecutive adult female admissions to acute wards in Goodmayes Hospital were screened. The case notes were screened for mention of children, any actions taken on their behalf. in addition to a number of demographic and social factors.

Results The findings of the audit indicate that children of psychiatrically ill mothers do not receive the
\end{abstract}

attention they need, as indicated by the literature on the topic.

Implications More detailed case history-taking by the parent's psychiatrist and closer cooperation between adult and child psychiatry departments are suggested as two methods of addressing this need.

An audit was undertaken looking at the information obtained in case summaries with regard to children of index adult patients and whether the mental health needs of the children were being met. Data were gathered from the case notes of 